Revista Brasileira de Agricultura Irrigada v.7, no. 6, p. 349 - 357, 2013

ISSN 1982-7679 (On-line)

Fortaleza, CE, INOVAGRI - http://www.inovagri.org.br

DOI: $10.7127 /$ rbai.v7n600187

Protocolo 187.13 - 04/10/2013 Aprovado em 05/12/2013

\title{
RESPOSTA DO FEIJÃO AZUKI À ADUBAÇÃO NITROGENADA SOB IRRIGAÇÃO
}

Fabiano José de Campos Bastos ${ }^{1}$, Fernando Nobre Cunha ${ }^{2}$, Nathália Lopes Ribeiro ${ }^{3}$, Nelmício Furtado da Silva ${ }^{4}$, Anísio Corrêa da Rocha ${ }^{5}$ Marconi Batista Teixeira ${ }^{6}$

\section{RESUMO}

Objetivou-se nesse trabalho avaliar a resposta do feijão azuki irrigado por aspersão, às doses crescentes de adubação nitrogenada em cobertura em um solo vermelho distroférrico. $\mathrm{O}$ experimento foi desenvolvido nas condições de campo, na estação experimental do Instituto Federal Goiano - Câmpus Rio Verde - GO. Os tratamentos empregados foram: 0, 25, 50, 100 e $150 \mathrm{~kg}$ de $\mathrm{N} \mathrm{ha}^{-1}$, em cobertura. Cada um dos tratamentos foi submetido a regimes de $100 \%$ de irrigação, aplicou-se a quantidade de água necessária para o pleno desenvolvimento da cultura, baseando em uma lâmina de $500 \mathrm{~mm}$. O delineamento experimental foi o de blocos ao acaso com 5 tratamentos e 4 repetições. Cada unidade experimental apresentou parcelas de 4,0 $\mathrm{m}$ de comprimento por 3,0 $\mathrm{m}$ de largura $\left(12,0 \mathrm{~m}^{2}\right)$, com sete linhas espaçadas a $0,50 \mathrm{~m}$. Foram avaliadas as cinco linhas centrais, com área útil de $\left(10,0 \mathrm{~m}^{2}\right)$. A maior produtividade foi alcançada com o tratamento $100 \mathrm{Kg} \mathrm{N} \mathrm{ha}^{-1}$.

Palavras-chave: componentes produtivos, fertilizantes químicos, produtividade.

\section{RESPONSE TO BEAN AZUKI NITROGEN IN IRRIGATION}

\begin{abstract}
The experiment was conducted under field conditions, at the experimental station of the Federal Institute Goiano - Campus Rio Verde - GO. The treatments were the doses of 0, 25, 50,100 and $150 \mathrm{~kg} \mathrm{~N} \mathrm{ha}^{-1}$, in coverage. The $\mathrm{N}$ source used was the Urea. Each one of the treatments was submitted to regimes of $100 \%$ of irrigation, it was applied to the quantity of water required for the full development of crop, based on a depth of $500 \mathrm{~mm}$. The experimental design was a randomized complete block with 5 treatments and 4 repetitions.

\footnotetext{
${ }^{1}$ Mestrando em Ciências Agrárias - Agronomia, Instituto Federal Goiano - Câmpus Rio Verde, Rodovia Sul Goiana, Km 01, CEP: 75.901-170, Rio Verde - GO, e-mail: fabianojcbastos@gmail.com

${ }^{2}$ Mestrando em Ciências Agrárias - Agronomia, IFG - Câmpus Rio Verde, e-mail: fernandonobrecunha@hotmail.com

${ }^{3}$ Graduando em Agronomia, IFGoiano - Câmpus Rio Verde, e-mail: nathyagronomia@gmail.com

${ }^{4}$ Mestrando em Ciências Agrárias - Agronomia, IFGoiano - Câmpus Rio Verde, e-mail: nelmiciofurtado@gmail.com

${ }^{5}$ Eng. Agrônomo, Prof. Dr. em Agronomia, IFGoiano - Câmpus Rio Verde, e-mail: anisiorocha@yahoo.com.br

${ }^{6}$ Eng. Agrônomo, Prof. Dr. em Agronomia, IFGoiano - Câmpus Rio Verde, e-mail: marconibt@gmail.com
} 
Each experimental unit presented plots of $4.0 \mathrm{~m}$ long by $3.0 \mathrm{~m}$ wide $\left(12.00 \mathrm{~m}^{2}\right)$, with seven rows spaced $0.50 \mathrm{~m}$ were evaluated the five central lines, with a usable area of $\left(10 \mathrm{~m}^{2}\right)$. This work aimed to evaluate the response of the azuki pea irrigated by spraying, to increasing doses of nitrogen fertilization in coverage in a solo red distroferrico.

Keywords: productive components, chemical fertilizers, productivity.

\section{INTRODUÇÃO}

O feijão azuki (Vigna angularis) é uma espécie originária da China, onde é cultivada há séculos. É uma leguminosa muito popular no Japão, onde é usado em sua culinária. No Brasil, ainda é pouco conhecido, mas vem ganhando espaço, sobretudo pelos colonos japoneses na região de São Paulo (VIEIRA et al., 2000).

O feijão representa a principal fonte de proteínas das populações de baixa renda (MESQUITA et al., 2007) e constitui um produto de destacada importância nutricional, econômica e social (VIEIRA et al., 1998).

Na região do Sudoeste de Goiás, adaptase bem ao cultivo de primeira safra (semeadura em outubro ou novembro), chegando a produtividades de $1.638 \mathrm{~kg} \mathrm{ha}^{-1}$ (GUARESCHI et al., 2009).

A adubação com fertilizantes nitrogenados aumenta a produção de grãos pelo feijoeiro, em consequência do incremento nos componentes do rendimento, ou seja, no número de vagens por planta, no número de grãos por vagem e na massa de 100 grãos. Dentre esses componentes, o mais afetado pela adubação nitrogenado e também, mais diretamente correlacionado como aumento da produtividade é o número de vagens por planta (ANDRADE et al., 1998). Em levantamento feito por Rosolem et al. (1996), foi constatada variação muito ampla com relação à resposta do feijoeiro à adubação nitrogenada (30 a 150 $\mathrm{Kg} \mathrm{N} \mathrm{ha}{ }^{-1}$ ), sugerindo que a cultura pode responder a doses maiores que as atualmente recomendadas.

A eficiência do uso do nitrogênio $(\mathrm{N})$ em cereais no mundo é de apenas 33\%. Considerando os $67 \%$ de $\mathrm{N}$ que não são aproveitados, tem-se uma perda anual de 15,9 bilhões de dólares em fertilização nitrogenada (RAUNS; JOHNSON, 1999), em adição aos prováveis impactos negativos ao ambiente (SCHRÖDER et al., 2000). Dentre as consequências deste aumento, estão a elevação das perdas de nitrato do solo para os lençóis freáticos e para os sistemas marinhos, bem como dos gases que contém $\mathrm{N}$ na atmosfera (MATSON et al., 1998).

Ambrosano et al. (1996), avaliando a aplicação de $\mathrm{N}$ em cobertura no cultivo de feijão irrigado no inverno, constataram que a produtividade pode ser aumentada pela adição de $\mathrm{N}$, e que as doses únicas aplicadas em cobertura foram mais eficientes do que as aplicadas somente na semeadura, com melhor época de aplicação aos 25 DAE; de acordo com DOORENBOS \& KASSAN (1979), a necessidade de água do feijoeiro com ciclo de 60 a 120 dias varia entre 300 a 500 $\mathrm{mm}$. 
Em estudos de definição da época ideal para aplicação de $\mathrm{N}$ nas culturas, visando aumento da eficiência de seu uso e da produtividade, não têm sido constatadas diferenças entre aplicação antecipada ou posterior; ainda que a produtividade do feijoeiro seja considerada mais satisfatória com a aplicação da dose total na semeadura; entretanto alguns autores relatam que $o$ aproveitamento desse nutriente é maior quando aplicado em cobertura, enquanto outros verificaram que a adubação nitrogenada parcelada, em cobertura é vantajosa para a cultura do feijão (AIDAR; KLUTHCOUSKI 2009; BARBOSA FILHO et al., 2009; ROSOLEM, 1996; ARAÚJO et al., 1994).

O manejo adequado da adubação nitrogenada representa uma das principais dificuldades da cultura do feijoeiro, visto que a aplicação de doses excessivas de $\mathrm{N}$, além de aumentar o custo econômico, pode promover sérios riscos ao ambiente, e a sua utilização em quantidade insuficiente pode limitar o seu potencial produtivo, mesmo que outros fatores de produção sejam otimizados (SANTOS et al., 2003).

Diante disso, torna-se de extrema importância estudos que busquem sistemas de manejo da adubação nitrogenada que visem à maximização dos lucros, redução dos impactos ambientais, causados pela adubação excessiva. Dessa forma, conhecer a cultura e sua capacidade de resposta à adubação nitrogenada é muito importante.

Objetivou-se nesse trabalho avaliar a resposta do feijão Azuki irrigado por aspersão, às doses crescentes de adubação nitrogenada em cobertura em um Latossolo Vermelho distroférrico.

\section{MATERIAS E MÉTODOS}

O experimento foi desenvolvido nas condições de campo, na estação experimental do Instituto Federal Goiano - Câmpus Rio Verde - GO. As coordenadas geográficas do local de instalação são $17^{\circ} 48^{\prime} 28^{\prime \prime}$ S e 5053'57" $\mathrm{O}$ com altitude média de 720 metros. O clima da região é classificado conforme Köppen; Geiger (1928), como Aw (tropical), com chuva nos meses de Outubro à Maio, e com seca nos meses de Junho à Setembro. A temperatura média anual entre 20 e $35^{\circ} \mathrm{C}$ com precipitações variando de 1.500 a $1.800 \mathrm{~mm}$ anuais o relevo é suave ondulado ( $10 \%$ de declividade). O solo foi classificado como Latossolo Vermelho distroférrico (LVdf), de textura média (EMBRAPA, 2006).

A adubação (Fósforo - Super fosfato simples e potássio - Cloreto de potássio), foi realizada a lanço antecipadamente 15 dias antes da semeadura, sem incorporação, de acordo com a análise de solo (tabela 1) e as recomendações da Embrapa (2004), para a cultura do feijão comum (Phaseolus vulgaris).

Tabela 1. Atributos químicas do solo da área experimental, Latossolo Vermelho Distroférrico, na camada de $0-20 \mathrm{~cm}$ de profundidade antes da implantação do experimento.

Macronutrientes

$$
\begin{aligned}
& \begin{array}{lllllllllllllllll}
\text { Prof. } & \mathrm{P} & \mathrm{M} . \mathrm{O} & \mathrm{pH} & \mathrm{K} & \mathrm{Ca} & \mathrm{Mg} & \mathrm{H}+\mathrm{Al} & \mathrm{S} & \mathrm{T} & \mathrm{Al} & \mathrm{V}
\end{array} \\
& \text { (cm) } \begin{array}{ccc}
\mathrm{mg} / & \mathrm{g} / & \mathrm{em} \\
\mathrm{dm} & \mathrm{dm}^{3} & \text { água }
\end{array}
\end{aligned}
$$

pH em água destilada, extrator de P, K, Mehlich ${ }^{-1}$. M.O matéria orgânica, $\mathrm{T}$ capacidade de troca de cátions, $\mathrm{S}+$ $\mathrm{H}+\mathrm{Al}$. V porcentagem de saturação de bases, V=100 $\mathrm{S} / \mathrm{T}$. 
Antes da realização da semeadura, as sementes foram tratadas com inseticida a base de thiamethoxam $350 \mathrm{~g} \mathrm{~L}^{-1}$, na dose de 200 $\mathrm{ml}$ do produto comercial para $100 \mathrm{~kg}$ de semente.

A semeadura foi realizada no dia 28 de abril de 2012, manualmente. O espaçamento utilizado foi de $0,50 \mathrm{~m}$ entre linhas e densidade de 12 sementes/m linear, densidade populacional de 240.000 plantas ha ${ }^{-1}$.

$\mathrm{O}$ delineamento experimental foi o de blocos ao acaso com 5 tratamentos e 4 repetições. Cada unidade experimental foi composta de parcelas de 4,0 $\mathrm{m}$ de comprimento por 3,0 m de largura $\left(12,0 \mathrm{~m}^{2}\right)$, com sete linhas espaçadas a $0,50 \mathrm{~m}$. Foram avaliadas as cinco linhas centrais, com área útil de $\left(10 \mathrm{~m}^{2}\right)$.

Os tratamentos foram as doses de 0, 25, 50,100 e $150 \mathrm{~kg} \mathrm{ha}^{-1}$ de $\mathrm{N}$ em cobertura. A fonte de $\mathrm{N}$ utilizada foi a Uréia (46-00-00). A adubação de cobertura foi realizada 35 dias após a emergência (DAE), aplicados manualmente distribuídos a lanço dentro de cada parcela de maneira uniforme.

Cada um dos tratamentos foi submetido a regimes de $100 \%$ de irrigação, aplicando-se a quantidade de água necessária para o pleno desenvolvimento da cultura, baseando em uma lâmina de $500 \mathrm{~mm}$.

Antes da instalação da cultura, realizouse um teste de uniformidade de aplicação de água em função de se corrigir qualquer irregularidade no sistema e aplicar com maior exatidão a mesma lâmina de água para todos os tratamentos utilizados.
Utilizou-se um sistema de irrigação por aspersão convencional fixo, composto por dois ramais com tubulação de $20 \mathrm{~mm}$ interligados paralelamente à linha principal do sistema (50 $\mathrm{mm}$ ). A subida do aspersor foi composta por mangueira de polietileno $(20 \mathrm{~mm})$ com altura de $1,5 \mathrm{~m}$ em relação à superfície do solo. Aspersores Duro Plastic ${ }^{\circledR}$, modelo D148 (setorial) com diâmetro de bocal de $2,8 \mathrm{~mm}$, vazão de $0,55 \mathrm{~m}^{3} \mathrm{~h}^{-1}$, raio de alcance de $11,8 \mathrm{~m}$ e altura de trabalho igual a $1,5 \mathrm{~m}$. O sistema de bombeamento foi composto por: bomba Thebe, modelo R 20 mancal, série 9710 015; motor Kohlbach 10 cv trifásico, voltagem 220 / 380 V e amperagem 26/15 A.

A irrigação foi manejada de forma a manter o solo sempre dentro da capacidade de campo. A fim de se obter uma menor interferência dos fatores climáticos, a irrigação foi realizada sempre pela manhã e no final da tarde.

O controle de pragas, doenças e ervas daninha foi realizado de acordo com as recomendações necessárias, para um bom desempenho da cultura.

A colheita foi realizada manualmente 120 DAE, onde as parcelas foram trilhadas e a umidade corrigida para $10 \%$ b.u.

Avaliaram-se os componentes produtivos: número de vagem por planta, número de grãos por vagem, massa de cem grãos, produtividade, rendimento em grãos e índice de colheita. Todos os dados observados foram submetidos à análise de variância de regressão a $5 \%$ de probabilidade. 


\section{RESULTADOS E DISCUSSÃO}

Os componentes produtivos, massa de cem grãos, número de vagens por planta e produtividade foram significativos; indicando efeito das doses de nitrogênio em cobertura.

Stone; Moreira (2001) verificaram que o número de vagens por planta, massa de cem sementes e produtividade do feijoeiro responderam significativamente a doses crescentes de $\mathrm{N}$, aplicados aos $35 \mathrm{DAE}$, sob o sistema de plantio direto.

Tabela 2. Resumo da análise de variância dos componentes produtivos do feijão azuki irrigado (NGV- Número de grãos por vagem; PROD- Produtividade em $\mathrm{Kg} \mathrm{ha}^{-1}$; IC- Índice de colheita).

\begin{tabular}{ccccc}
\hline F.V & G.L & NGV & PROD & IC \\
\hline Dose & 4 & $0,9888700^{* *}$ & $190270,7^{* * *}$ & $0,1095575^{* *}$ \\
Bloco & 3 & $0,1341650^{\text {ns }}$ & $4917,346^{* *}$ & $0,2001833^{\text {ns }}$ \\
\hline Resíduo & 12 & 0,9655667 & 905,7710 & 0,7564167 \\
\hline Média Geral & 0,539 & 203,48 & 0,018 \\
Desvio padrão & 0,120 & 45,50 & 0,0039 \\
Erro padrão & 6,30 & 8,49 & 6,39 \\
C.V. & 8,55 & 2396,29 & 0,275 \\
\hline
\end{tabular}

${ }^{\text {ns }}$ não significativo; ${ }^{*}{ }^{* * *}$ significativo respectivamente a 1 e $5 \%$ de probabilidade.

O NGV em função da adubação nitrogenada em cobertura adequou-se a uma relação cúbica, com $\mathrm{R}^{2}$ de $88,5 \%$, indicando que $11,5 \%$ das variações de NGV não são explicadas pela variação da adubação nitrogenada em cobertura.

Para número de grãos por vagem, Figura 1, pode-se notar que os tratamentos $50 \mathrm{~kg} \mathrm{ha}^{-1}$ de $\mathrm{N}$ e $150 \quad \mathrm{~kg}^{-1}$ de $\mathrm{N}$ apresentaram desempenho bastante similar no que diz respeito a esta variável, ainda a $\operatorname{sim}$ o tratamento com $150 \mathrm{~kg} \mathrm{ha}^{-1}$ de $\mathrm{N}$ foi $2,83 \%$ superior ao tratamento $50 \mathrm{~kg} \mathrm{ha}^{-1}$ de $\mathrm{N}$. Entretanto verificou-se nos tratamentos $25 \mathrm{e}$ $100 \mathrm{~kg} \mathrm{ha}^{-1} \mathrm{~N}$ a menor diferença, sendo está de apenas $2,2 \%$.

$\mathrm{O}$ tratamento $0 \mathrm{~kg} \mathrm{ha}^{-1}$ de $\mathrm{N}$, demonstrou a menor média e uma diferença de $4,2 \%$ para a dose de $25 \mathrm{~kg} \mathrm{ha}^{-1} \mathrm{~N}$. O número de vagens e o número de grãos por planta são os componentes de rendimento mais afetados por variações na densidade de plantas na linha de plantio, e pelo espaçamento entre linhas. Tais variações nem sempre estão relacionadas com o rendimento de grãos (SHIMADA et al., 2000). O que corrobora com o fato de a dose de 50 e $150 \mathrm{~kg}$ $\mathrm{ha}^{-1}$ de $\mathrm{N}$ apresentarem um comportamento similar. Entre as deficiências nutricionais que ocorrem na cultura do feijão, a de $\mathrm{N}$ é a mais frequente, devendo-se precisar a dose e época corretas, de modo a propiciar boa nutrição da planta no momento em que ainda é possível aumentar o número de grãos e de vagens por planta, ou seja, até o início do florescimento (CARVALHO et al., 2001).

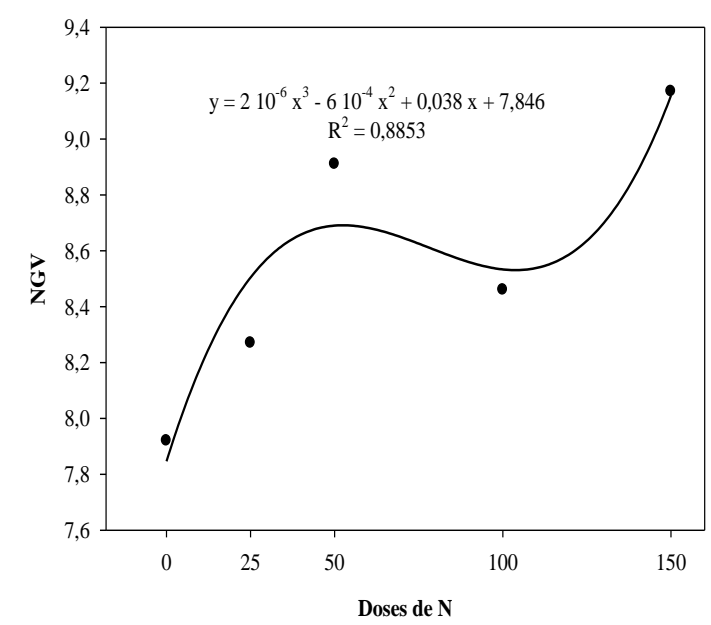

Figura 1. Número de grãos por vagem em função da adubação nitrogenada em cobertura. 
A produtividade em função da adubação nitrogenada em cobertura foi a que mostrou maior $\mathrm{R}^{2}$ dentre as variáveis avaliadas, $\log$ foi a que adequou-se melhor a uma relação cúbica, com $\mathrm{R}^{2}$ de $93 \%$, assim a produtividade apresentou alta relação com a adubação nitrogenada em cobertura, deste forma devido ao comportamento da curva bem típico com pontos máximos e mínimos bem definidos pode-se verificar de maneira satisfatória a resposta do feijão azuki as doses de $\mathrm{N}$ em cobertura.

Reichert (2012) observou influência na produtividade quando se acrescenta nitrogênio independentemente da quantidade de $\mathrm{N}$ aplicado na cultura, além disso também verificou que isso ocorre principalmente quando este elemento é acrescentado na cultura, como adubação de cobertura, ocorre elevação na produtividade, mostrando que a cultura responde a esta tecnologia.

A maior produtividade foi alcançada com o tratamento $100 \mathrm{~kg} \mathrm{ha}^{-1}$ de $\mathrm{N}\left(2.740 \mathrm{~kg} \mathrm{ha}^{-1}\right)$, onde verificou-se uma diferença de 11,67\% para a dose de $50 \mathrm{Kg} \mathrm{ha}^{-1}$ de $\mathrm{N}$ (Figura 2). Mostrando produtividade superior a alcançada por Guareschi et al. (2009), na qual foi de $1.638 \mathrm{~kg} \mathrm{ha}^{-1}$.

Soratto et al. (2006) constataram que a aplicação de $0,25,50,75$ e $100 \mathrm{~kg} \mathrm{ha}^{-1}$ de $\mathrm{N}$ em cobertura, aos 15, 25 e 35 DAE proporcionou melhor desenvolvimento e aumentos da produtividade da cultura do feijão irrigado, cultivado em sistema de plantio direto.
A produtividade superior obtida pode ter ocorrido graças ao incremento da irrigação, o que pode levar a planta a aproveitar melhor a adubação com $\mathrm{N}$ em cobertura, aumentando sua eficiência e diminuindo as perdas, principalmente por volatilização no experimento em condições de campo. Os tratamentos 0 e $150 \mathrm{~kg}$ $\mathrm{ha}^{-1}$ de $\mathrm{N}$ em cobertura (mínima produtividade) aproximaram-se indicando uma diferença de apenas $2,85 \%$, evidenciando o efeito negativo da dose de $150 \mathrm{~kg} \mathrm{ha}^{-1}$ de $\mathrm{N}$ que praticamente se equiparou com a testemunha $0 \mathrm{~kg} \mathrm{ha}^{-1}$ de $\mathrm{N}$ em cobertura.

As produtividades intermediárias foram observadas nas doses de 25 e $50 \mathrm{~kg} \mathrm{ha}^{-1}$ de $\mathrm{N}$ em cobertura, as quais apresentaram uma diferença baixa de apenas $0,89 \%$.

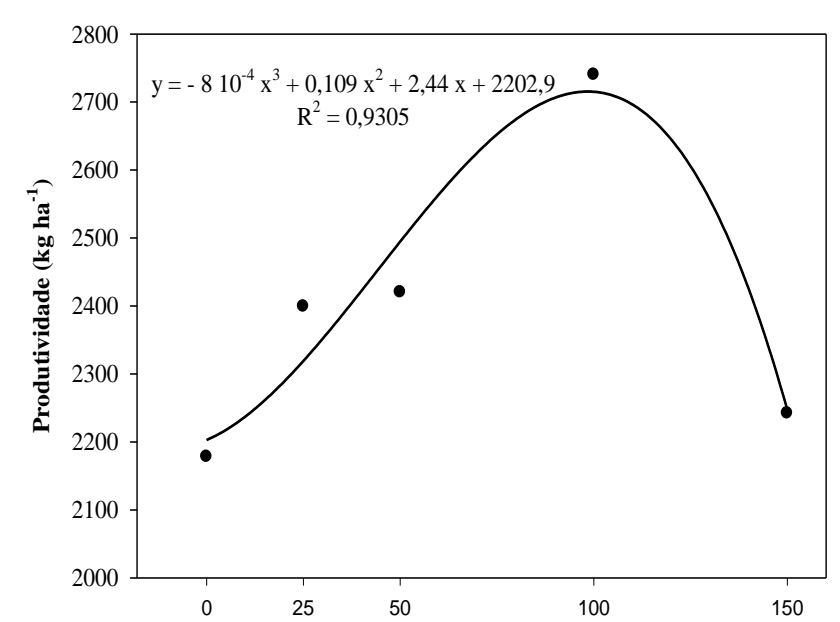

Figura 2. Produtividade de feijão Azuki, em função das doses de adubação nitrogenada em cobertura.

O Índice de colheita (IC) não demonstrou o mesmo comportamento de adequação ao modelo cúbico observado no NGV e produtividade, pois mostrou um $\mathrm{R}^{2}$ baixo de aproximadamente $59,7 \%$, o que é devido 
principalmente a uma queda no IC na dose de $50 \mathrm{Kg} \mathrm{ha}^{-1}$ de $\mathrm{N}$ em cobertura.

Para IC o tratamento que mais de destacou foi o $0 \mathrm{~kg} \mathrm{ha}^{-1}$ de $\mathrm{N}$, figura 3. Esse tratamento teve o maior índice de colheita (IC) indicando maior eficiência na translocação de biomassa para os grãos, porém nos tratamentos 0 e $25 \mathrm{~kg} \mathrm{ha}^{-1}$ de $\mathrm{N}$ observou-se uma reduzida diferença de aproximadamente $1,7 \%$, enquanto que os maiores valores de IC foram verificados nos tratamentos de 0 e $50 \mathrm{~kg} \mathrm{ha}^{-1}$ de $\mathrm{N}$, a qual foi entorno de 14,3\%. Evidências indicam que o índice de colheita é um caráter relativamente estável de uma cultivar (SPAETH et al., 1984), e que a maior parte da variância genotípica na produção de grãos de feijão está associada a variações na produção de biomassa e não no índice de colheita (SCULLY \& WALLACE, 1990).

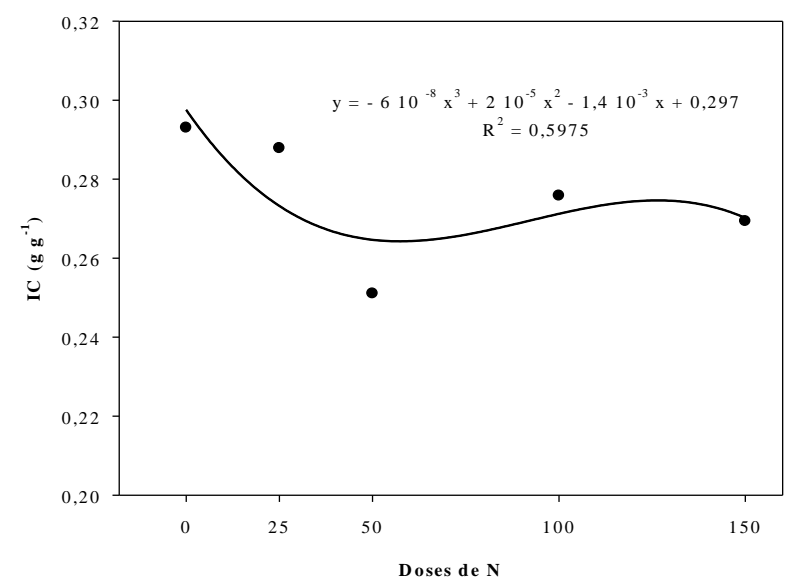

Figura 3. Componente produtivo do feijão Azuki; Índice de colheita (IC) em função das doses de adubação nitrogenada em cobertura.

No mundo é crescente a preocupação com a poluição dos recursos hídricos e da atmosfera, pelo uso de fertilizantes nitro- genados, em virtude deste nutriente estar sujeito a perdas por erosão, lixiviação, volatilização e desnitrificação (PANG et al., 1997; CABEZAS et al., 2000, além do elevado custo energético para obtenção dos mesmos. Tendo em vista os custos ambientais e econômicos e o fato de que o Brasil importa atualmente cerca de $70 \%$ da uréia utilizada na agricultura, se faz necessário encontrar alternativas viáveis que visem à redução no seu uso; assim aplicação da dose de $\mathrm{N}$ em cobertura ideal para o feijão azuki é de $100 \mathrm{Kg} \mathrm{ha}^{-1}$, já a dose de $150 \mathrm{Kg} \mathrm{ha}^{-1}$ de $\mathrm{N}$ em cobertura é excessiva, $\log$ a a não utilização desta dose evita gastos desnecessário promovendo economia de $\mathrm{N}(66,67 \%)$.

\section{CONCLUSÃO}

O feijão Azuki responde à adubação nitrogenada em cobertura até $100 \mathrm{~kg} \mathrm{ha}^{-1}$ de $\mathrm{N}$ em cobertura.

O componente produtivo NGV não se mostrou sensível para quantificar produtividade do feijão Azuki nas condições que foram realizadas este trabalho.

A produção de matéria seca, especialmente o aumento da parte aérea não está correlacionada com o aumento do índice de colheita.

$O$ índice de colheita foi superior no tratamento com dose $0 \mathrm{~kg} \mathrm{ha}^{-1}$ de $\mathrm{N}$ em cobertura, mostrando uma baixa produção de matéria seca de parte aérea.

A produtividade do feijão Azuki com 
dose $0 \mathrm{~kg} \mathrm{ha}^{-1}$ de $\mathrm{N}$ em cobertura, mostrou-se satisfatória atingindo entorno de até $2180 \mathrm{~kg}$ ha $^{-1}$, mostrando uma boa capacidade desta planta em fazer fixação biológica de $\mathrm{N}$.

De maneira geral, em virtude do habito de crescimento indeterminado do feijão Azuki se torna muito difícil correlacionar os componentes produtivos com a produtividade.

\section{REFERÊNCIAS BIBLIOGRÁFICAS}

AIDAR, H.; KLUTHCOUSKI, J. Manejo da adubação nitrogenada. In: Kluthcouski $\mathrm{J}$ et al. Fundamentos para uma agricultura sustentável, com ênfase na cultura do feijoeiro, p.268-288. 2009.

AMBROSANO, E. J.; WUTKE, E. B.; AMBROSANO, G. M. B.; BULISANI, E. A.; BORTOLETTO, N.; MARTINS, A. L. M.; PEREIRA, J. C. V. N. A.; SORDI, G. Efeito do nitrogênio no cultivo de feijão irrigado no inverno. Scientia Agricola, v. 53, p. 338-342, 1996.

ANDRADE, M. J. B.; DINIZ, A. R.; CARVALHO, J. G.; LIMA, S. F. Resposta da cultura do feijoeiro à aplicação foliar de molibdênio e às adubações nitrogenadas de plantio e cobertura. Ciência e Agrotecnologia, Lavras, v.22, n.4, p.499- 508, 1998.

ARAÚJO, F.F. Cultivo em escala comercial. In: HUNGRIA, M. \& ARAÚJO, R.S., eds. Manual de métodos empregados em estudos de microbiologia agrícola. Brasília, Empresa Brasileira de Pesquisa Agropecuária, 1994. p.149-155.

BARBOSA FILHO, M. P.; COBUCCI, T.; FAGERIA, N. K.; MENDES, P. N. Época de aplicação de nitrogênio no feijoeiro irrigado monitorada com auxílio de sensor portátil. Ciênc. agrotec. 2009, vol.33, n.2, pp. 425-431. ISSN 1413-7054.
CARVALHO, M.A.C.; ARF, O.; SÁ, M.E.; BUZETTI, S.; SANTOS, N.C.B.; BASSAN, D.A. Produtividade e qualidade de sementes de feijoeiro (Phaseolus vulgaris L.) sob influência de parcelamentos e fontes de nitrogênio. Revista Brasileira de Ciência do Solo, v.25, p.617-624, 2001.

DOOREMBOS, J.; KASSAN, A. H. Field response to water. Rome: FAO, 1979. 193p. (Irrigation and Drainage Paper, 33).

EMPRESA BRASILEIRA DE PESQUISA AGROPECUÁRIA - EMBRAPA. Centro Nacional de Pesquisa de Solos. Sistema brasileiro de classificação de solos. 2.ed. Rio de Janeiro, Embrapa Solos, 2006. 306p.

EMPRESA BRASILEIRA DE PESQUISA AGROPECUÁRIA - EMBRAPA. Cerrado. Brasília, DF; Empresa Brasileira de Pesquisa Agropecuária: Embrapa Informações Tecnológicas, 2004. 416p.

GUARESCHI, R. F.; ARAUJO, M. J. C.; GAZOLLA, P. R.; ROCHA, A. C. Produtividade de feijão azuki em função de doses de potássio em cobertura. Global Science and Technology, v. 02, n.02, p.67 $72,2009$.

KÖPPEN, W.; GEIGER, R. Klimate der Erde. Gotha: Verlag Justus Perthes. 1928. Wall-map $150 \mathrm{~cm} \times 200 \mathrm{~cm}$.

CABEZAS, W. A. R. L.; TRIVELIN, P. C. O.; KORNODÔRF, G. H.; PEREIRA, S. Balanço da adubação nitrogenada sólida e fluida de cobertura na cultura do milho em sistema plantio direto no Triângulo Mineiro. Revista Brasileira de Ciência do Solo, Viçosa, v. 14, p. 363-376, 2000.

MATSON, P. A.; NAYLOR, R.; MONASTERIO, O. Integration of environmental, agronomic, and economic aspects of fertilizer management. Science, v.280, n.3, abr., 1998.

MESQUITA, F. R.; CORRÊA, A. D.; ABREU, 
C. M. P. de.; LIMA, R. A. Z.; ABREU, A. F. B. de. Linhagens de feijão (phaseolus vulgaris L.): composição química e digestibilidade protéica. Ciência e Agrotecnologia, v. 31, p. 114-1121, 2007.

PANG, X. P.; LETEY, J.; WU, L. Irrigation quality and uniformity and nitrogen application effects on crop yield and nitrogen leaching. Soil Science Society of America Journal, Madison, v. 61, p. 257-261, 1997.

RAUNS, W. R.; JOHNSON, G. V. Improving nitrogen use efficiency for cereal production. Agronomy journal, Madison, v. 91, n.3, p. 357-363, 1999.

REICHERT, P. Cultura do feijão e nitrogênio no sistema de produção integração lavourapecuária. Produção Vegetal. Dissertação. Universidade Estadual do Centro-Oeste, Guarapuava-PR, 2012.

ROSOLEM, C. A. Calagem e adubação mineral. In: ARAÚJO, R. S.; RAVA, C. A.; STONE, L. F.; ZIMMERMANN, M. J. O. Cultura do feijoeiro comum no Brasil. Piracicaba: POTAFOS, 1996. p. 353-385.

SANTOS, A.B.; FAGERIA, N.K.; SILVA, O.F. \& MELO, M.L.B. Resposta do feijoeiro ao manejo de nitrogênio em várzeas tropicais. Pesq. Agropec. Bras., 38:1265-1271, 2003.

\section{SCHRÖDER J.J., NEETESON J.J., OENEMA} O., STRUIK P.C. Does the crop or the soil indicate how to save nitrogen in maize production? Field Crops Research 62, 151-164. 2000.
SCULLY, B. T.; WALLACE, D. H. Variation and relationship of biomass, growth rate, harvest index, and phenology to yield of common bean. Journal of the American Society for Horticultural Science, Alexandria, v. 115 , p. 218-225, 1990.

SHIMADA, M. M.; ARF, O.; SÁ, M. E. Componentes do rendimento e desenvolvimento do feijoeiro de porte ereto sob diferentes densidades populacionais. Bragantia, v. 59, n. 02, p. 181-187, 2000.

SORATTO, R. P.; CARVALHO, M. A., ARF, O. Nitrogênio em cobertura no feijoeiro cultivado em plantio direto. Revista Brasileira de Ciência do Solo, v. 30, p. 259-265, 2006.

SPAETH, S. C.; RANDALL, H. C.; SINCLAIR, T. R.; VENDELAND, J. S. Stability of soybean harvest index. Agronomy Journal, Madison, v.76, p.482-486, 1984.

STONE, L.F.; MOREIRA, J.A.A. Resposta do feijoeiro ao nitrogênio em cobertura, sob diferentes lâminas de irrigação e preparos do solo. Pesquisa Agropecuária Brasileira, v.36, p.473-481, 2001.

VIEIRA, C.; PAULA JÚNIOR, T. J. de; BORÉM, A. Feijão: Aspectos gerais e cultura no Estado de Minas. Viçosa: Universidade Federal de Viçosa, 1998. 596 p.

VIEIRA, R. F.; VIEIRA, C.; MOURA, W. M. Comportamento do feijão azuki em diferentes épocas de plantio em Coimbra e Viçosa, Minas Gerais. Revista Ceres, v.47, n.272, p. 411-420, 2000. 